
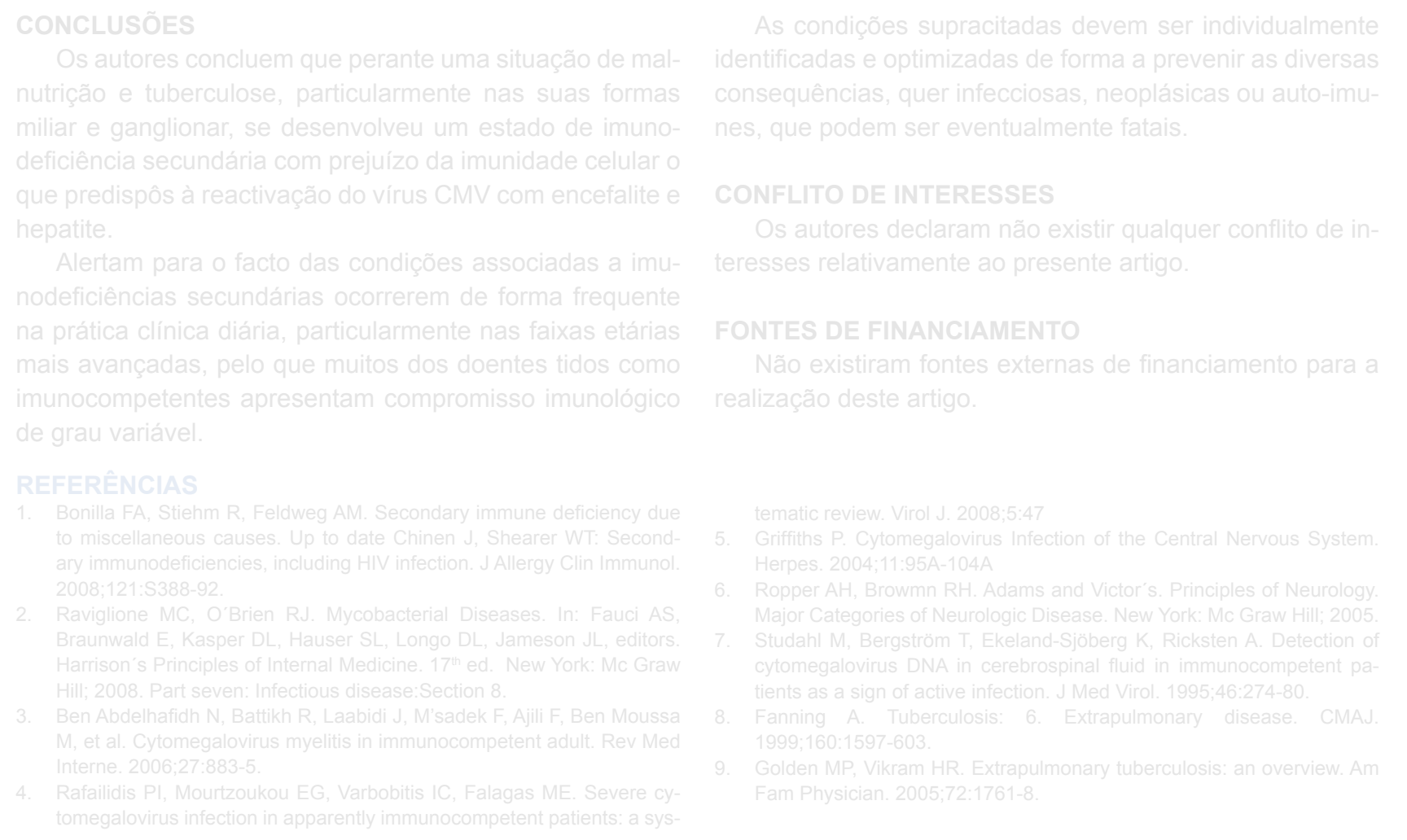

\title{
Panmielose Aguda com Mielofibrose: Uma Causa Rara de Pancitopenia
}

\author{
Acute Panmyelosis with Myelofibrosis: \\ A Rare Cause of Pancytopenia
}

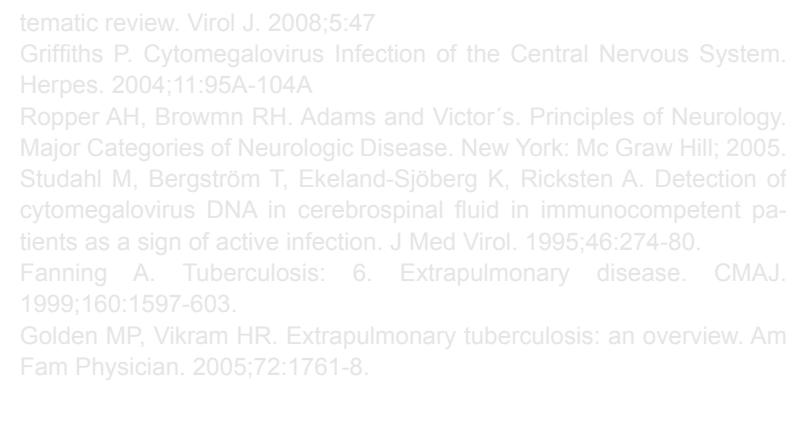

\author{
Cláudia FALÉ ${ }^{1}$, Ana ARAUJO'1 , Sílvia LOURENÇO ${ }^{1}$, Maria PAIS ${ }^{1}$ \\ Acta Med Port 2013 Sep-Oct;26(5):613-616
}

\section{RESUMO}

Panmielose aguda com mielofibrose é uma forma rara e agressiva de Leucemia mielóide aguda que corresponde a $2 \%$ de todas as leucemias agudas. Clinicamente caracteriza-se por um início abrupto de citopenias, associadas a extensa fibrose da medula óssea e uma proliferação de percussores das três séries mieloides (panmielose). O seu rápido curso, ao contrário de outras hemopatias de carácter insidioso não se acompanha de esplenomegalia sugestiva de hematopoese extramedular ou alterações dismórficas da série rubra com o aparecimento de dacriocitos. O desafio diagnóstico na panmielose aguda com mielofibrose resulta do diagnóstico diferencial quer com síndromes mielodisplasicos associados a mielofibrose quer com outras leucemias agudas. Reportamos o caso de um jovem de 16 anos, internado por pancitopenia, cuja marcha diagnostica, conduziu ao diagnóstico de panmielose aguda com mielofibrose. A exposição deste caso justifica-se pela raridade desta patologia associada aos escassos casos descritos na literatura, permitindo uma partilha clinica e melhor compreensão desta entidade de difícil diagnóstico.

Palavras-chave: Leucemia Mieloide Aguda; Mielofibrose Primária; Síndromes Mielodisplásicos.

\section{ABSTRACT}

Acute Panmyelosis with myelofibrosis is a rare and aggressive acute myeloid leukemia accounting for $2 \%$ of all acute leukemias. Clinically, it is characterized by an acute onset of cytopenias associated with extensive bone marrow fibrosis in the absence of splenomegaly and related morphological changes in the red blood cells such as dacryocytes. The presence of fibrosis further complicates the correct diagnosis of this rare disease, being important to differentiate this entity from other hematologic malignancies such as other acute myeloid leukemias and myelodysplastic syndromes associated with myelofibrosis. We report a case of a young adult of 16 years old, admitted with severe pancytopenia. The exposure of this case is justified by the rarity of this pathology associated with few cases reported in medical literature, allowing for a clinical sharing and a better understanding of the different clinical aspects of this entity of difficult diagnosis.

1. Serviço de Medicina. Hospital do Espírito Santo. Évora. Portugal.

Recebido: 26 de Novembro de 2012 - Aceite: 22 de Maio de 2013 | Copyright @ Ordem dos Médicos 2013 
Keywords: Leukemia, Myeloid, Acute; Primary Myelofibrosis; Myelodysplastic Syndromes.

\section{INTRODUÇÃO}

Define-se pancitopenia, como uma diminuição do número total de elementos celulares circulantes no sangue periférico (eritrócitos, leucócitos e plaquetas), que clinicamente cursa com anemia, neutropenia e trombocitopenia. Não sendo uma situação frequente é potencialmente grave e de etiologia por vezes difícil de estabelecer, obrigando a uma exaustiva marcha diagnostica. O presente caso clínico ilustra uma causa particular de pancitopenia num jovem que conduziu ao diagnóstico de uma forma rara e agressiva de leucemia mielóide aguda denominada de Panmielose aguda com mielofibrose (PMAF).

\section{CASO CLÍNICO}

Doente sexo masculino, raça branca, 16 anos de idade, internado por quadro clínico com 15 dias de evolução caracterizado por febre, associada a queixas inespecíficas de astenia e anorexia. À admissão, o doente apresentava-se febril $\left(39^{\circ}\right)$, com palidez cutânea. Auscultação cardio-pulmonar sem alteração. Sem evidência de adenopatias ou organomegalias.

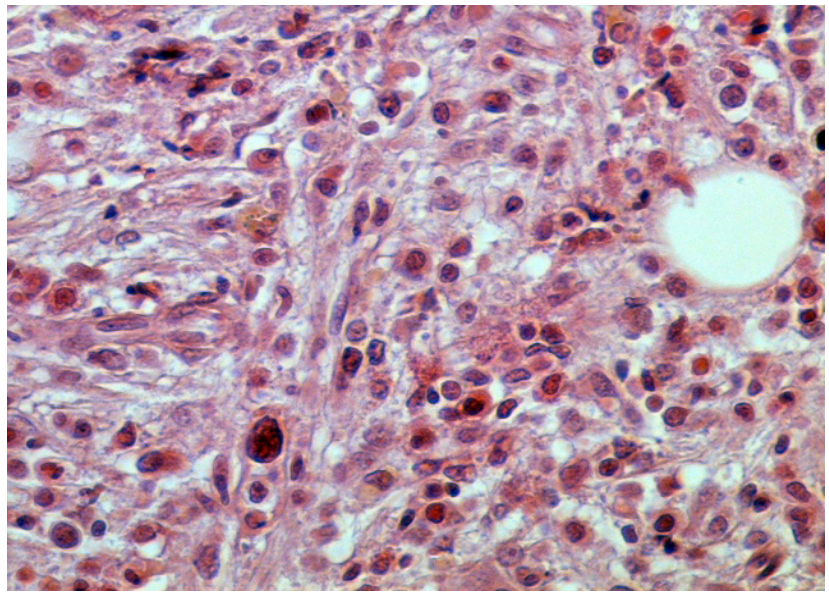

Figura 1 - Biópsia medular que evidencia uma medula óssea displásica associada a extensa fibrose, com substituição de grande parte dos adipócitos medulares, (hematoxilina/eosina, ampliação original $\times 400)$.

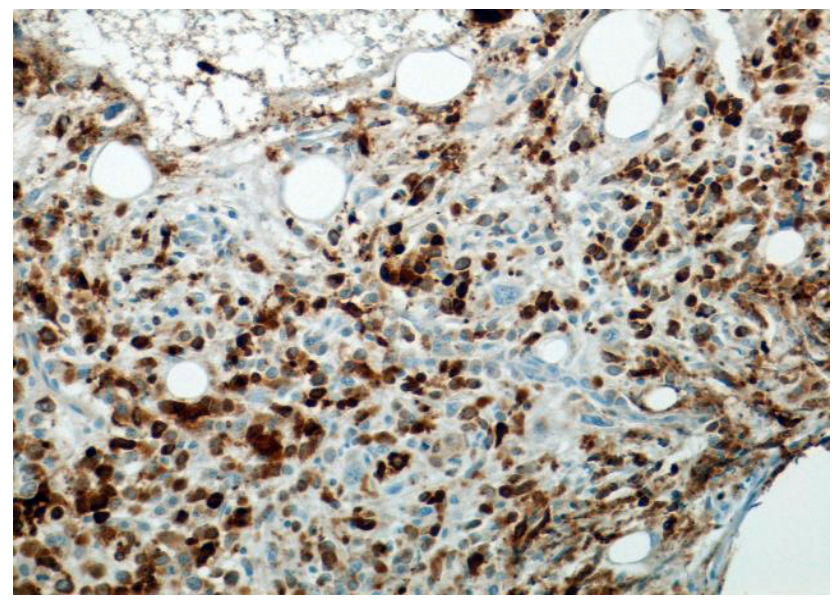

Figura 3 - Imunohistoquímica para CD 68.
Analiticamente revelava quadro grave de pancitopénia: anemia hipocrómica, microcítica (Hb: 6,5 g/dl, VGM: 73,5 FL, HGM: 24,6 pg), leucopénia com neutropénia (Leucócitos: $2800 \times 10^{3} / /$, Neutrófilos: $700 \times 10^{9} /$ l) e trombocitopénia $\left(51000 \times 10^{3} / l\right)$. Esfregaço de sangue periférico sem alterações. Restantes resultados destacava-se aumento dos parâmetros inflamatórios: PCR: $10 \mathrm{mg} / \mathrm{dl}, \mathrm{VS}$ : $140 \mathrm{~mm}$ e dalactato desidrogenase $(707 \mathrm{mg} / \mathrm{dl})$ Proteinograma com hipergamaglobulinemia policlonal. TAC tóraco-abdómino-pélvica sem evidência de lesões focais ou organomegalias.

No internamento foi iniciada antibioterapia no contexto de neutropénia febril. Do estudo etiológico da pancitopenia, foram pedidas serologias infecciosas (CMV; EBV; B19, HIV; febre Q, Leishmaniose, Brucelose, febre escaro nodular, tuberculose) que se revelaram negativas assim como o estudo auto imune (lúpus eritematoso sistémico). Hemoculturas seriadas sem agente identificado. Medulograma de difícil execução, tendo sido considerado uma punção seca, não sendo possível a realização de Imunofenotipagem e estudo citogenético da medula óssea (MO). Realizada biopsia

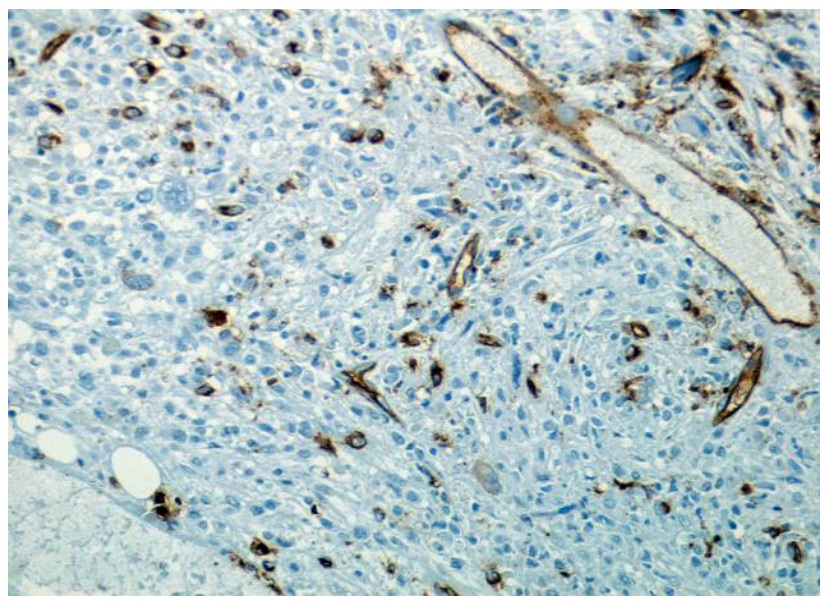

Figura 2 - Imunohistoquímica para CD34.

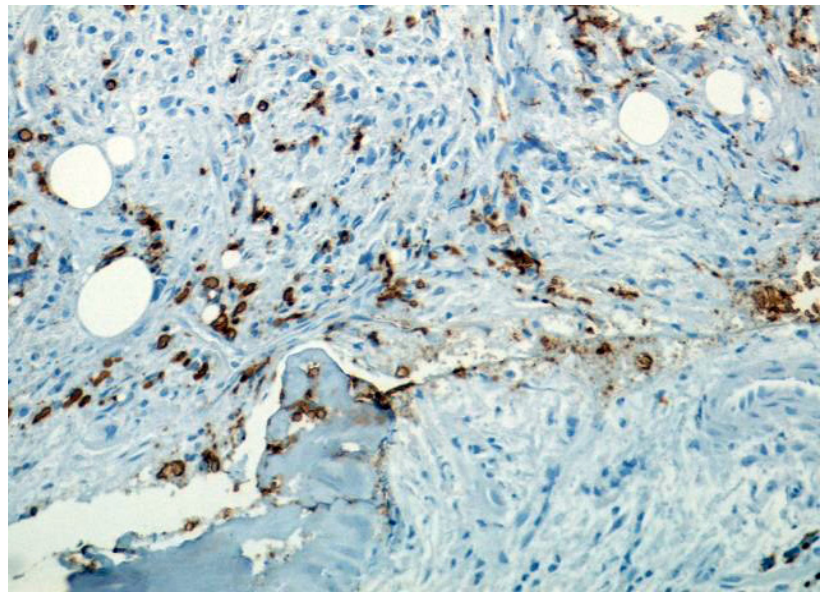

Figura 4 - Imunohistoquímica para glicoferina. 
óssea que revelou uma M.O hipercelular, com hiperplasia e displasia das três linhagens mielóides associada a extensa fibrose reticulínica (Fig. 1). O estudo imunohistoquímico mostrou uma percentagem de bastos de $20 \%$ que expressavam o marcador inicial CD34 + (Fig. 2). Esta população blastica, mieloperoxiadase negativa, caracterizava-se por ser uma proliferação trilinear, em proporção variada, identificada por um painel de anticorpos marcadores da série mielomonocitica (Fig. 3), da série eritróide (Fig. 4) e da série megacarocitica. Estes dados, confirmaram uma proliferação panmieloide, excluindo uma proliferação unilinear o que, associado ao início agudo do quadro clínico, suportou o diagnóstico final de PMAF. O doente foi submetido a quimioterapia, com refractariedade e sem recuperação hematológica, ocorrendo o óbito três meses após o diagnóstico.

\section{DISCUSSÃO}

A Pancitopenia não constitui um problema clínico frequente e o seu aparecimento leva a equacionar múltiplos diagnósticos diferenciais (Tabela 1). Apesar das causas mais frequentes serem a doença crónica hematológica, a possibilidade de ser devida a uma doença hematológica aguda existe e deverá ser excluída.

No presente caso, tratando-se de um quadro agudo em doente jovem, considerou-se primeiramente a hipótese de se tratar de patologia infecciosa. De entre a patologia infecciosa são os vírus, nesta faixa etária, que mais comumente são responsáveis por quadros de falência medular, nomeadamente o CMV e B19.

Apos exclusão de causa infecciosa, a pancitopenia grave, que o doente apresentava, impunha a realização de mielograma, para exclusão de patologia aguda, dado a febre e/ou infecção serem sintomas frequentes na apresentação inicial de leucemia aguda. A punção seca apontou o diagnóstico para causa neoplásica, sendo a biopsia óssea o exame gold standard que conduziu ao diagnóstico final. A evidência de uma MO hipercelular, associada a displasia trilinear e extensa fibrose reticulínica, em presença de um número de células blásticas superior a $20 \%$, que clinicamente cursou com um caracter agudo, levou ao diagnóstico de PMAF
Esta entidade clinica, definida em 2001, na classificação de neoplasias dos tecidos linfóides e hematopoéticos da OMS corresponde a $2 \%$ de todas as leucemias agudas, afectando sobretudo adultos, embora se encontrem descritos casos em doentes mais jovens. ${ }^{1}$ A patogénese da PAMF é desconhecida. Sabe-se que existem com frequência alterações citogenéticas associadas, embora muito variáveis. ${ }^{2}$ Clinicamente o quadro é agudo, agressivo e rapidamente progressivo, caracterizando-se por um início abrupto de citopenias, associadas a extensa fibrose da medula óssea e uma proliferação de percussores das três linhagens mielóides (panmielose). O seu rápido curso, ao contrário, de outras hemopatias malignas de carácter insidioso, faz com que não se acompanhe de esplenomegalia sugestiva de hematopoese extramedular ou alterações dismórficas da série rubra sugestivas de mielofibrose, com o aparecimento de dacriocitos. ${ }^{3}$ A presença de extensa fibrose medular dificulta o correcto diagnóstico, sendo importante diferenciar esta entidade não só de outras leucemias mielóides agudas que também cursam com mielofibrose, nomeadamente a Leucemia megacarioblástica aguda com mielofibrose e a Leucemia mielóide aguda relacionada com mielodisplasia e mielofibrose, como também de Síndromes mielodisplasicos associados a mielofibrose. ${ }^{4}$ A Leucemia megacarioblástica aguda associa-se a uma percentagem de blastos> $20 \%$ em que mais de $50 \%$ são megacarioblastos. Em contraste a PAMF caracteriza-se por ser uma proliferação trilinear em que os blastos são mais heterogéneos, menos diferenciados, expressam o marcador CD34 e a maior parte não expressa antigénios megacarióciticos ${ }^{3 ; 4} A$ presença de blastos mieloperoxidase negativos na PAMF também distingue esta entidade dos outros subtipos de LMA em que os blastos são mieloperoxidases positivos. Se o processo mieloproliferativo for predominantemente de um tipo celular como por exemplo de mieloblastos, ao qual se associa mielofibrose medular, deverá ser designado de leucemia mielóide aguda associada a mielodisplasia e mielofibrose e não de PAMF. ${ }^{4} \mathrm{~A}$ ausência de dacriocitos e de esplenomegalia, que reflecte um curso crónico e um maior número de blastos, permite a distinção com mielofibrose primária. Mais difícil é a distinção entre PMAF e Síndromes mielodisplasi-

Tabela 1 - Causas de pancitopenia:

\section{Distúrbios da medula óssea}

Distúrbios não medulares
Lupus eritematoso sistémico

Infecção: TP, HIV, Leishmaniose, Brucelose, CMV, B19

Mielodisplasia

Leucemia aguda

Mielofibrose
Deficiência nutricional (anemia megaloblástica)

latrogénica: fármacos, quimioterapia citotóxica, radiação ionizante, 
cos associados a um excesso de blastos e mielofibrose. Clinicamente a PMAF pode ser separada dos Síndromes mielodisplasicos pelo início agudo e histologicamente pelo facto de a $\mathrm{MO}$ apresentar um maior número de megacariócitos e de blastos.

\section{CONCLUSÃO}

Embora a PMAF não seja uma causa comum de pancitopénia sobretudo no jovem, onde a causa infecciosa e de prognóstico habitualmente favorável prevalece, esta existe devendo ser considerada no diagnóstico diferencial. O ponto crucial e o grande desafio diagnóstico da PMAF consiste na conjugação de elementos clínicos e de diagnóstico que

\section{REFERÊNCIAS}

1. Thiele J, Kvasnicka H, Schmitt-Graef F: Acute Panmyelosis with lymphoma. Leuk Lymphoma. 2004;45:681-7.

2. Suvajdzic N, Marisavljevic D, Kraguljac N, Pantic M, Djordjevic V Jankovic G, et al. Acute Panmyelosis with Myelofibrosis: clinical immunophenoypic and cytogenetic study of twelve cases. Leuk Lymphoma. 2004;45:1873-9. reconhecem um processo agudo com infiltração suficiente de blastos (superior a 20\%) associado a extensa fibrose medular, hiperplasia e displasia das três séries mielóides. A biopsia óssea com estudo imunohistoquímico é o exame gold standard para o correcto diagnóstico.

\section{CONFLITO DE INTERESSES}

Os autores declaram não ter nenhum conflito de interesses relativamente ao presente estudo.

\section{FONTES DE FINANCIAMENTO}

Os autores declaram não nenhum financiamento relativamente ao presente estudo.
3. Orazi A, O'Malley DP, Jiang J, Vance GH, Thomas J, Czader M, et al. Acute panmyelosis with myelofibrosis: an entity distinct from acute megakaryoblastic leukemia. Mod Pathol. 2005;18:603-14.

4. Campo E, Swerdlow SH, Harris NL, Pileri S, Stein H, Jaffe ES. The 2008 WHO classification of lymphoid neoplasms and beyond: evolving concepts and practical applications. Blood. 2011;117:5019-32.
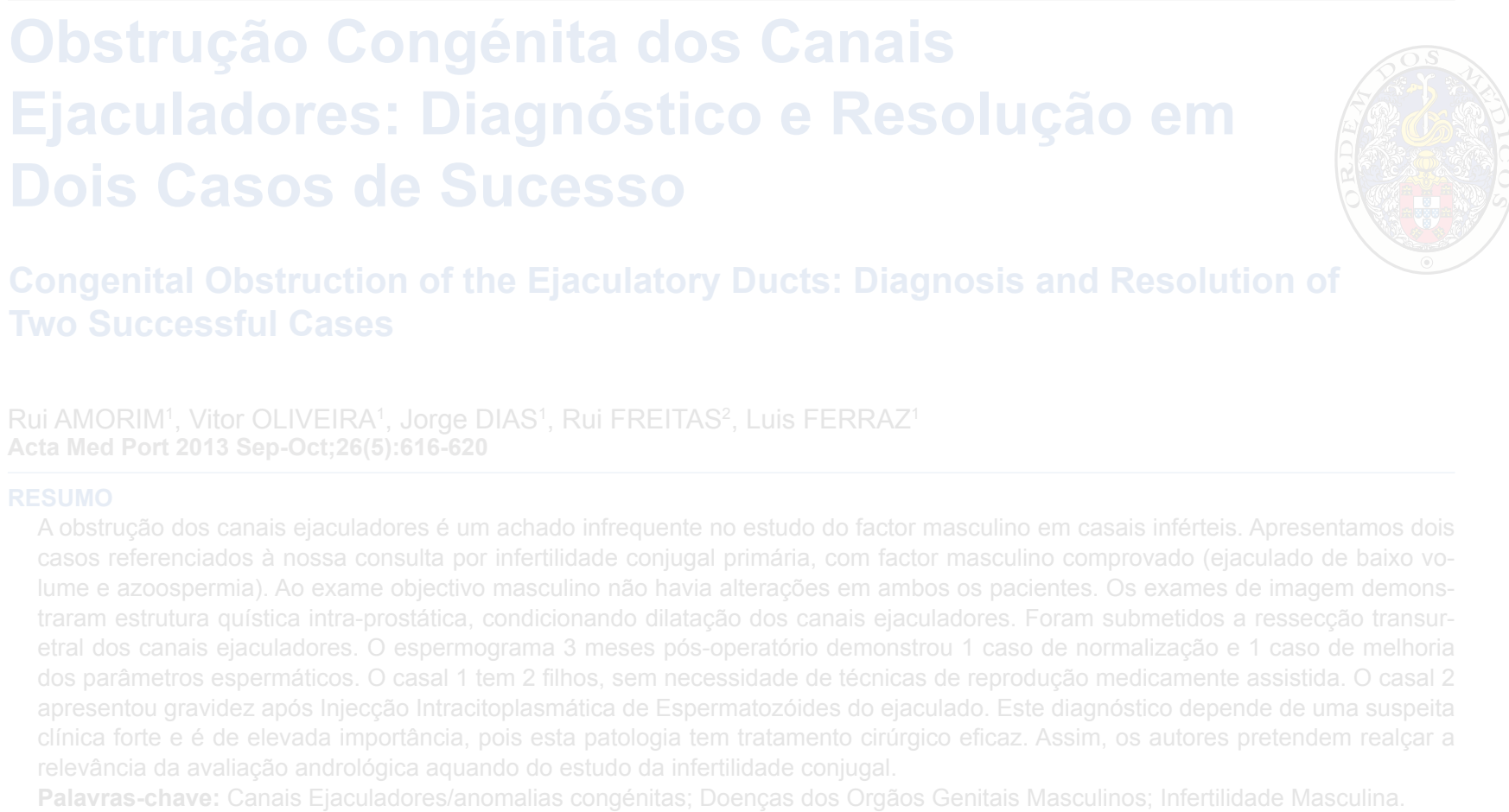